Das ärztliche Berufsgeheimnis schützt die Vertrauensbeziehung zwischen Arzt und Patient - auch im Gefängnis. Und eben diese vertrauensvolle Beziehung, gemeinsam mit den bereits heute möglichen Ausnahmen, bietet auch der öffentlichen Sicherheit den bestmöglichen Schutz. Deshalb unterstützt die FMH die Forderung der Ärztegesellschaft des Kantons Genf, das Arztgeheimnis zu bewahren.

Weil in der Diskussion um das Arztgeheimnis dessen Bedeutung vielfach verkannt, aber auch die Rolle des Gefängnisarztes missverstanden wird, beleuchten Dr. med. Pierre-Alain Schneider und Prof. Dr. iur., Dr. med. Philippe Ducor in dieser Ausgabe der SÄZ das Thema aus ärztlicher und juristischer Sicht.

Dr. med. Jürg Schlup, Präsident der FMH

\title{
Das Arztgeheimnis erklären
}

\section{Pierre-Alain Schneider}

Dr. med., Präsident der Société Médicale de la Suisse Romande (SMSR)

Vor längerer Zeit habe ich einmal gegen einen Medizinprofessor aufbegehrt, der den Hippokratischen Eid als überholte Tradition bezeichnete. Sicherlich wollte er damit sagen, dass der Patient für Versicherer und Statistiker sehr transparent geworden ist. Ich wies ihn darauf hin, dass der Eid immerhin in der Genfer Deklaration des Weltärztebundes zu grossen Teilen fortlebt. Unsere Patienten vertrauen uns, weil sie wissen, dass sie auf unsere Verschwiegenheit zählen können. Der Wunsch, unsere Tätigkeit ökonomisch zu kontrollieren, ändert daran nichts. Das Arztgeheimnis ist ein Privileg, das wir Gesundheitsdienstleister mit Anwälten und Geistlichen teilen. Seine Bedeutung und sein Wert sind seit Jahrhunderten anerkannt. Die Geheimhaltungspflicht ist im Strafgesetzbuch verankert; ein Verstoss dagegen stellt kein Kavaliersdelikt dar, sondern kann sogar mit Freiheitsentzug bestraft werden.

Es gibt allerdings Ausnahmen, die man kennen sollte, wie den rechtfertigenden Notstand. Dass dieser den Ärzten durch entsprechende Änderungen an mehreren kantonalen Ausführungsgesetzen zum Strafgesetzbuch

Unsere Patienten vertrauen uns, weil sie wissen, dass sie auf unsere Verschwiegenheit zählen können.

in Erinnerung gerufen werden soll, ist erfreulich. Die Ärzte jedoch zu zwingen, jeden Umstand zu melden, den man a posteriori als Alarmzeichen einstufen könnte, hiesse, sie zum Handlanger der Vollzugsbehörde zu machen und den Hippokratischen Eid endgültig zu begraben. Die Naivität des Gesetzgebers ist erstaunlich. Ärztinnen und Ärzte können schliesslich keine Gedanken lesen! Sie können auch nicht den konsequenten Vollzug von Haftmassnahmen ersetzen.

Was die Öffentlichkeit fordert, ist Sicherheit. Die Morde an Lucie, Marie und Adeline haben die Bevölkerung erschüttert, und niemand möchte ein solches Drama noch einmal erleben. Die Behörden müssen handeln, aber bitte mit Weitsicht. Im Genfer Fall kommen die Berichte Ziegler und Chappuis zu einem eindeutigen Schluss: Das Arztgeheimnis hat hier keinerlei Rolle gespielt. Das Problem war, dass man einem Häftling aufgrund seiner guten Führung zu früh vertraut hat, ohne dass ein psychiatrisches Gutachten je verfasst und abgewartet wurde. Dabei wurde die Vielschichtigkeit solcher Psychopathen ausser Acht gelassen. Das Opfer selbst war Therapeutin; ich glaube kaum, dass

\section{Dem Arzt eine Meldepflicht aufzuerlegen} hiesse, ihn zum Handlanger der Vollzugsbehörde zu machen.

sie sich in die Höhle des Löwen gewagt hätte, wenn sie eine unmittelbare Gefahr vermutet hätte.

Selbst Psychiater, die in der Lage sind, bestimmte Mechanismen hinter den Taten psychisch Auffälliger zu erkennen, geben zu, keine sicheren Prognosen zur langfristigen Entwicklung solcher Personen abgeben zu können. Nun kann sich aber unser Rechtssystem nicht mit Unsicherheiten zufriedengeben; das ist seine Schwäche, wenn es um solche Straftäter geht. So kann es passieren, dass die kürzlich verhängte lebenslange Verwahrung von Maries Mörder durch die Rekursinstanz aufgehoben wird.

Die Genfer Ärzte haben eine kantonale Initiative angestossen, um statt einer Informationspflicht der Ärzte die Informationsmöglichkeit des aktuellen Systems beizubehalten, und zwar ohne Sanktionsrisiko, wenn es um gefährliche Gefängnisinsassen geht. Es wird nicht leicht zu erklären sein, warum das Arztgeheimnis der Sicherheit dient und den Ärzten die Entscheidung zu überlassen ist, wann sie einen beunruhigenden Umstand melden. Die Kampagne wird anspruchsvoll sein und muss die Öffentlichkeit überzeugen, dass die Informationspflicht die gefährliche Illusion nährt, Rückfälle liessen sich verhindern. Dabei spielt man bei diesen besonderen Häftlingen stets mit dem Feuer! 